\title{
VECTORIAL ANALYSIS OF THE ELECTROCARDIOGRAM IN COMMON VENTRICLE*
}

\author{
BY \\ LARRY P. ELLIOTT, HERBERT D. RUTTENBERG, ROBERT S. ELIOT, \\ AND RAY C. ANDERSON \\ From the Department of Pediatrics, University of Minnesota, Minneapolis, and the Department of Pathology, \\ The Charles T. Miller Hospital, St. Paul, Minnesota, U.S.A.
}

Received December 27, 1962

Electrocardiographic findings with common cardiac ventricle have been described by a number of investigators (Brown, 1950; Rogers and Edwards, 1951 ; Campbell, Reynolds, and Trounce, 1953; Neill and Brink, 1955; Sodi-Pallares and Calder, 1956; Nadas, 1957; Keith, Rowe, and Vlad, 1958; Taussig, 1960; and Van Praagh, Zacharioudakis, and Keith, 1962). Vectorial analysis has, however, received no comprehensive evaluation. Thus, it seemed appropriate to study, from a vectorial viewpoint, the electrocardiographic features encountered in 21 subjects with this condition.

In the series of 21 cases of common ventricle studied, transposition of the great vessels occurred in each case. Anatomical details from these cases form part of another report (Elliott, Anderson, and Edwards, 1964) in which there were additional anomalies involving the position of the infundibular chamber, pulmonary valve, and atrio-ventricular valves. Therefore it is essential that we define the condition common ventricle as used in this report.

In the condition common cardiac ventricle with transposed great vessels, there is one ventricular chamber into which both (when there are two) atrio-ventricular (A-V) valves empty. The same ventricular chamber gives rise to the pulmonary trunk and, through its infundibular chamber, to the transposed aorta (Fig. 1).

In each case of common cardiac ventricle, the infundibular chamber was located anteriorly at the base of the heart, in one of two positions. When the infundibulum was located at the right aspect of the base of the heart, it was considered to be "non-inverted" (Fig. 1, left). When the infundibulum was located at the left aspect of the base of the heart, it was considered "inverted" (Fig. 1, right). These two types correspond to the non-inverted and inverted forms of mixed (Type 4) transposition as described by Spitzer (1951).

In some cases there was, in addition, obstruction to pulmonary flow owing to pulmonary valvular stenosis, or subpulmonary stenosis, or both. Furthermore, in some cases certain abnormalities of the atrio-ventricular valves coexisted, such as common A-V valve, tricuspid atresia, or mitral atresia.

\section{SUBJECTS AND METHODS}

There were 21 patients ( 15 dead; 6 living) with common ventricle and transposed great vessels. Necropsy specimens were available in the 15 patients who had died. In each of the 6 living patients, there was inversion of the infundibulum, intact A-V valves, and no obstruction to pulmonary flow. These features were documented by selective angiocardiography and cardiac catheterization.

* This study was supported by Research grant HE-5694 of the National Heart Institute, United States Public Health Service. Dr. Ruttenberg is a Postdoctoral Research Fellow of the National Heart Institute, HF-13,715, United States Public Health Service. 

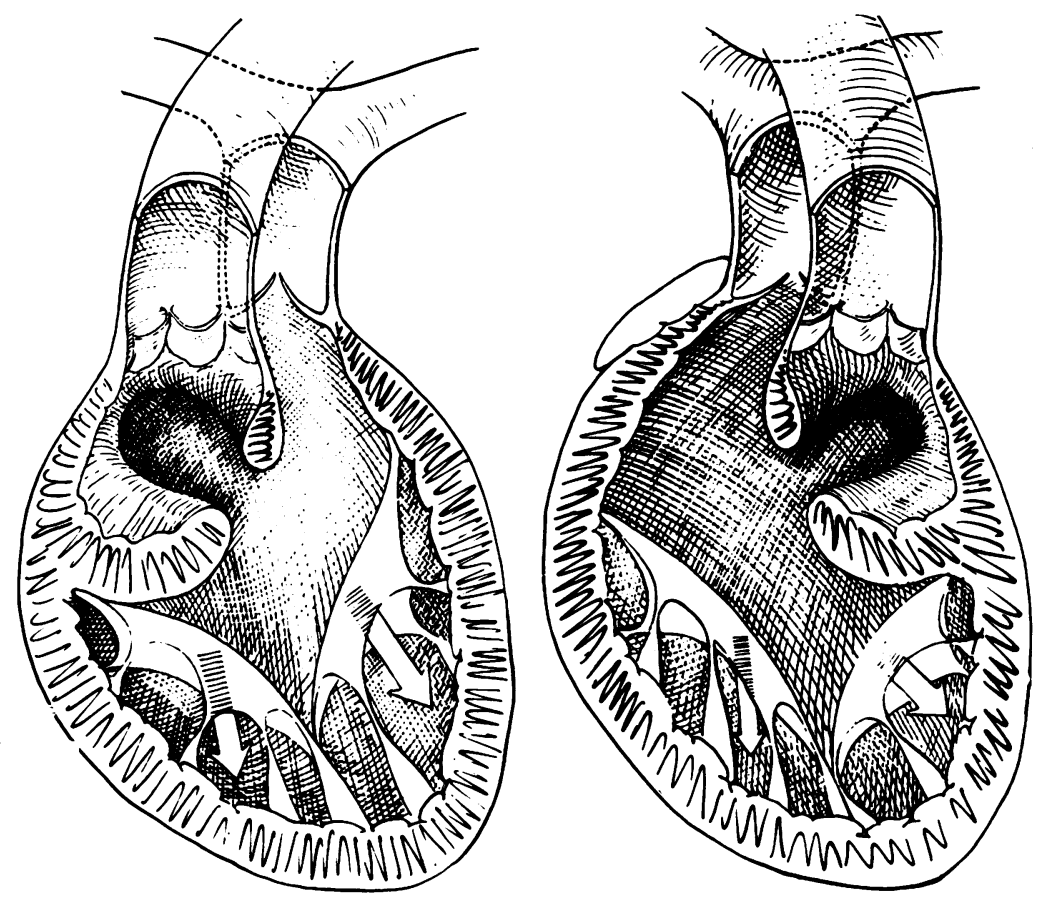

FIG. 1.-Diagrammatic representation of common ventricle with transposition showing the two positions occupied by the infundibulum, and the relation of the infundibulum to the common ventricle itself. Left. The infundibulum is located at the right side of the base of the heart in the so-called "noninverted" position. The transposed aorta arises from the infundibulum, and the pulmonary trunk, which is posterior and to the left of the aorta, arises from the main portion of the common ventricle. Both A-V valves (when there are two) empty into the common ventricle. Right. The infundibular chamber is located at the left side of the base of the heart, and is considered to occupy an "inverted" position. The transposed aorta arises from the infundibulum. The relation of the pulmonary trunk and the A-V valves to the common ventricle is like that illustrated in the picture on the left.

Electrocardiograms, available for each case, had been made with a Sanborn direct-writing multi-channel unit. Readings were made of the 12 conventional leads and, on occasion, lead V4R. In a few isolated cases, vectorcardiograms were available; these had been obtained using the vector method of Schmitt and Simonson (1955). These vectorcardiograms have been used to develop schemes and graphs of the information contained in various leads of the conventional tracings.

Of the 21 patients studied, 18 were male and 3 were female. The ages of the patients ranged from 1 month to 30 years: 2 were 1 month of age, 7 were between 1 and 6 months, 6 were between $1 \frac{1}{2}$ and 5 years, 5 were between 7 and 10 , and one was 30 .

In considering the entire series of 21 cases, it was decided to analyse the material in two ways: (1) according to the state of the atrio-ventricular valves (whether or not there was atresia of an A-V valve), and (2) according to the position of the infundibular chamber and the state of the pulmonary flow, that is, whether there was $(a)$ inversion or non-inversion of the infundibulum, and $(b)$ obstruction to pulmonary flow.

The electrocardiograms were studied in three ways. The first consisted in analysing the direction of the early QRS vectors during the first 0.1 to $0.02 \mathrm{sec}$. (initial cardiac vectors). The second consisted of a vectorial analysis of the QRS and T-wave complexes, and the third involved analysis of the electrocardiographic patterns, with respect to ventricular hypertrophy.

The hypertrophy patterns were divided into three types: (1) right ventricular hypertrophy, (2) left ventricular hypertrophy, and (3) "indeterminate". The designation of an indeterminate pattern of hypertrophy was considered appropriate as, in several instances, conventional tracings showed abnormalities of 


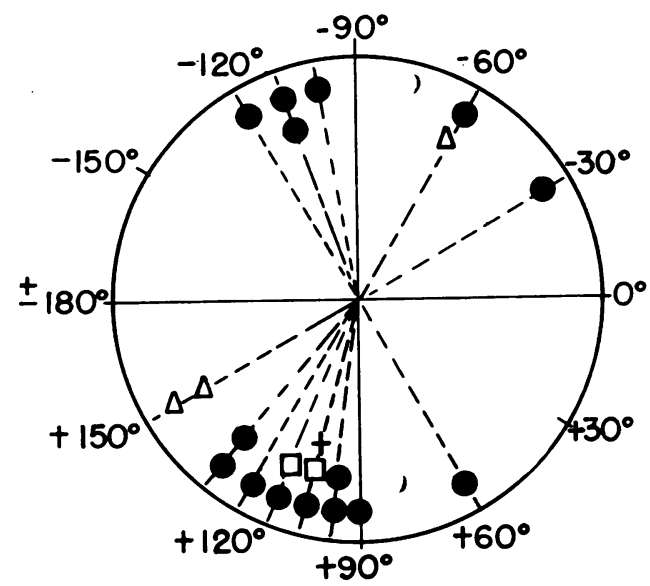

$O=$ Intact $A-V$ valves $\Delta=$ common $A-V$ valve $\square=$ Tricuspid atresia $t=$ Mitral atresio

FIG. 2.-The distribution of the $\hat{A} \mathbf{Q R S}$ axis in the frontal projection (standard and augmented limb leads) in 21 cases of common ventricle.

the QRS-T complex, that fell into no clearly recognized pattern of right, left, or combined ventricular hypertrophy.

The criteria employed for signs of ventricular hypertrophy were those proposed by Vince and Keith (1961) correlated with the normal values reported by Ziegler (1951).

\section{RESULTS}

I. Analysis According to Anatomy of Atrio-ventricular Valves. The mean QRS axis in the frontal projection (standard and augmented limb leads) for each individual case is shown in Fig. 2. Right

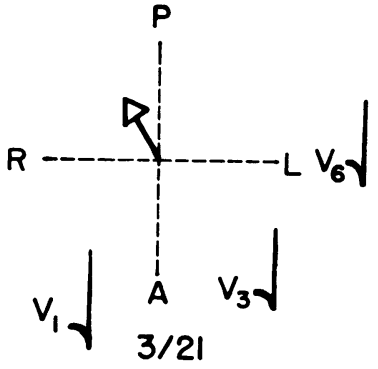

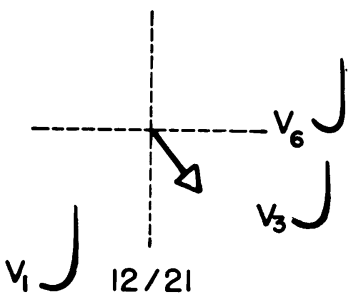

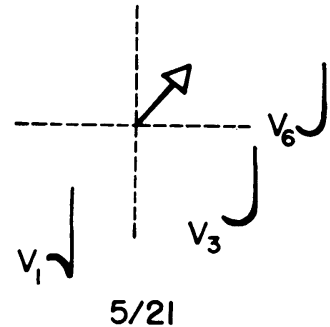

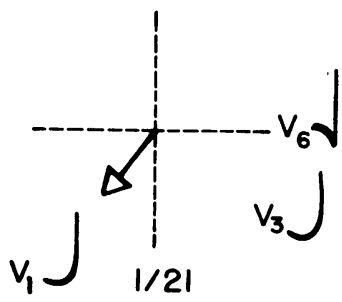

Fig. 3.-Incidence of different directions of the initial cardiac vectors in the horizontal projection, with the deflections these vectors would write on præcordial leads V1, V3, and V6 in 21 cases of common ventricle. $R=$ right; $P=$ posterior; $L=$ left; and $A=$ anterior. 


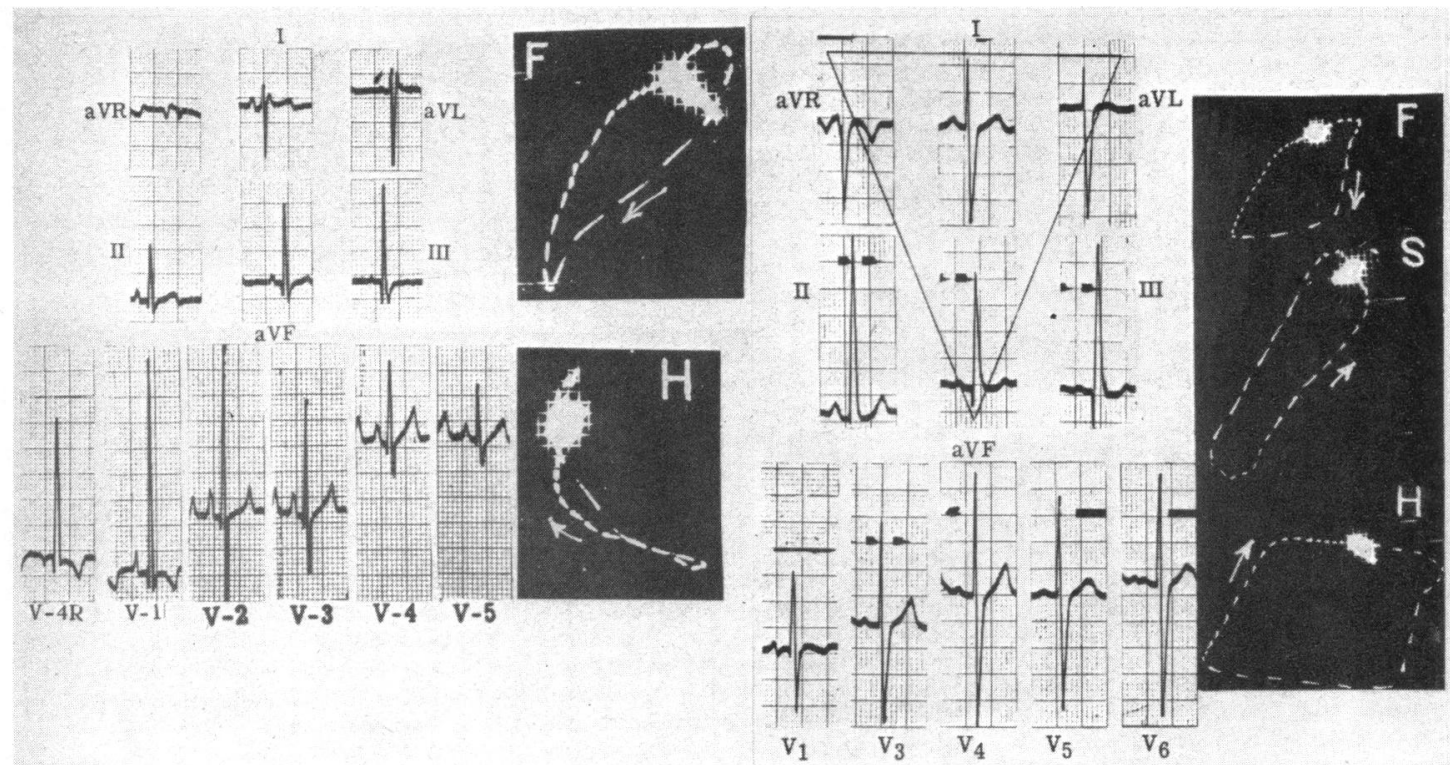

FIG. 4.-Electrocardiogram and vectorcardiogram in two cases of common ventricle. $F=$ frontal projection; $\mathrm{S}=$ left sagittal projection; $\mathrm{H}=$ horizontal projection. Left. 2-month-old female infant with intact $\mathrm{A}-\mathrm{V}$ valves, non-inversion of the infundibulum, and pulmonary stenosis. The initial vectors in the horizontal plane (H) are directed rightward and posteriorly, projected on all præcordial leads as a $Q$ wave. The QRS sE loop is narrow and directed anteriorly so that the main component of the loop is positive to the axis of all præcordial leads. This produces predominant $R$ waves in V4R-V6. Right. 5-year-old boy with intact A-V valves and inversion of the infundibulum. The QRS $\mathrm{SE}$ loop in the horizontal plane $(\mathrm{H})$ is wide open and directed anteriorly, represented as RS complexes in V1-V6. Note the Q in V1.

axis deviation for age was evident in 8 patients (4 with intact A-V valves, 2 with common A-V valve, and 2 with tricuspid atresia), normal axis in 6 (5 with intact A-V valves and 1 with mitral atresia), and left axis deviation in 7 (6 with intact $A-V$ valves and 1 with common A-V valve). Further analysis of the frontal projection showed that the QRS loop was inscribed clockwise in those patients with normal or right axis deviation, and counterclockwise in those with left axis deviation.

The initial cardiac vectors generated during the first 0.01 to $0.02 \mathrm{sec}$. of the QRS interval, as judged by vectorial analysis of the electrocardiogram, were directed as follows (Fig. 3).

(1) Initial vectors directed rightward and posteriorly were noted in 3 subjects (each with intact A-V valves). This is reflected in the scalar electrocardiogram as a $Q$ wave in præcordial leads V1 through V6 (Fig. 3, upper left and Fig. 4, left).

(2) Initial vectors directed leftward and posteriorly were noted in 5 subjects (each with intact A-V valves). This was represented by $Q$ waves confined to the right præcordial leads (Fig. 3, upper right and Fig. 4, right). In 2 of these 5 subjects, the initial vector exhibited pronounced magnitude in a superior direction, as judged by deep $Q$ waves in lead III.

(3) Initial vectors directed leftward and anteriorly in 12 subjects (6 with A-V valves, 3 with common A-V valve, 2 with tricuspid atresia, and 1 with mitral atresia). This was represented by absence of $Q$ waves in V1 through V6 (Fig. 3, lower left and Fig. 5, left). Thus, all cases with anomalies of the A-V valves showed a common pattern of the initial vector.

(4) Initial vectors were directed rightward and anteriorly in one subject (intact A-V valve). This was the only patient with $Q$ waves confined to the left præcordial leads of the electrocardiogram (Fig. 3, lower right and Fig. 5, right).

Electrocardiographic features of some form of ventricular hypertrophy were present in each case studied. 


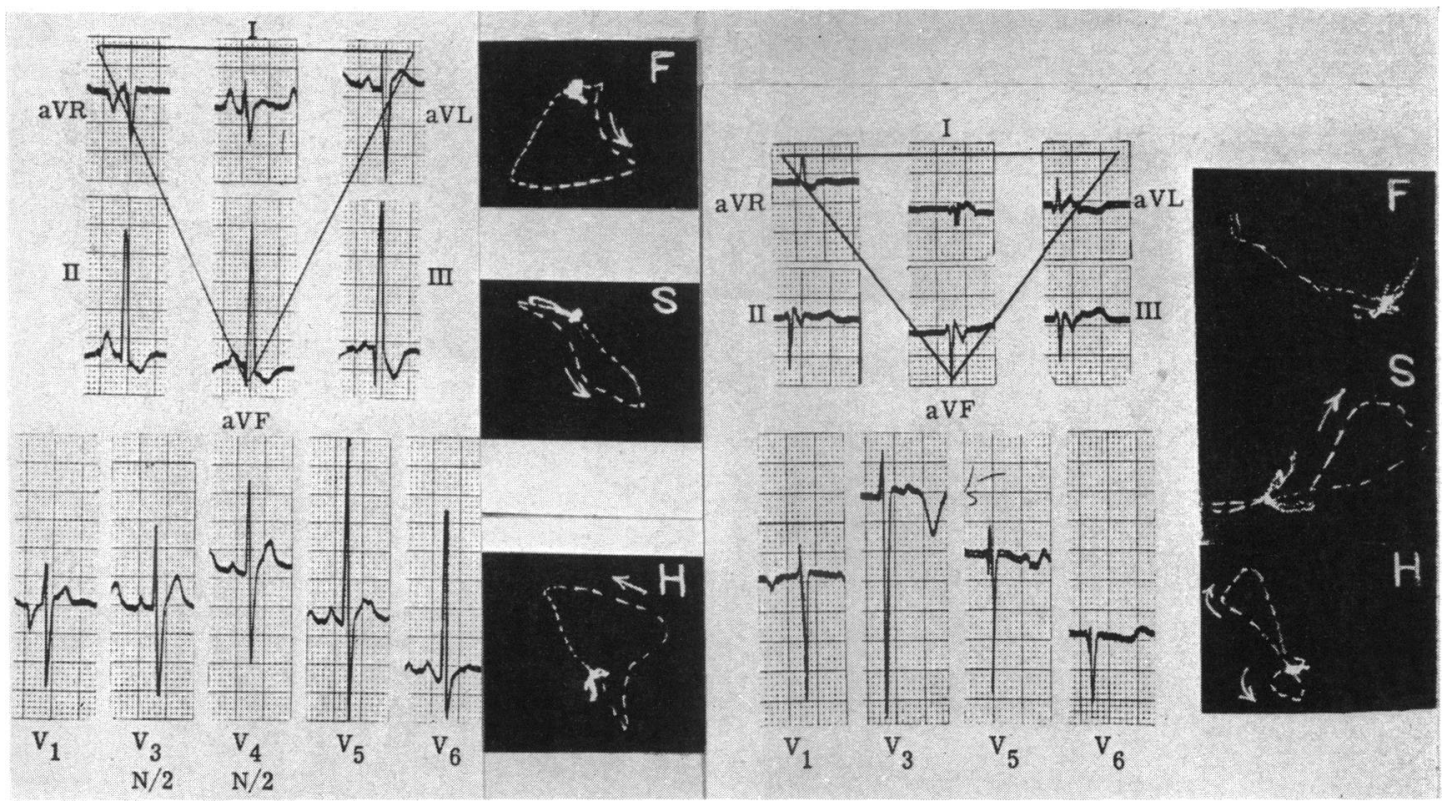

Fig. 5.-Electrocardiograms and vectorcardiograms in two cases of common ventricle. Abbreviations as in Fig. 4. Left. 11-year-old female infant with tricuspid atresia and non-inversion of the infundibulum. Discordance of the QRS loop and mean QRS vector between the frontal projection $(F)$ and horizontal projection $(H)$. Right. 8-year-old boy with intact A-V valves and inversion of the infundibulum. The only patient in whom the initial vectors were directed rightward and anteriorly, producing $Q$ waves in V5 and V6. The QRS sE loop in the horizontal projection $(\mathrm{H})$ is narrow and directed far posteriorly, producing $\mathrm{rS}$ complexes in leads V1-V6.

Diagnoses of left, right, and indeterminate ventricular hypertrophy were based on the findings in the horizontal projection, and not in conjunction with those in the frontal projection.

Right ventricular hypertrophy (RVH). Præcordial lead features of RVH were observed in 6 subjects ( 4 with intact $A-V$ valves, 1 with common $A-V$ valve, and 1 with tricuspid atresia). In these cases, the mean QRS vector was directed rightward and anteriorly as judged by tall $R$ waves in the right præcordial leads and $\mathrm{rS}$ complexes in V6 (Fig. 6, left).

It is apparent that in common ventricle there may be features similar to those of right ventricular hypertrophy in hearts with two ventricles. Recognizing this, the question may be asked whether in common ventricle with $\mathrm{RVH}$, there are signs that suggest the true anatomical situation of a common ventricle. In 1 of the 6 cases with $\mathrm{RVH}$, the electrocardiogram did not suggest the presence of a common ventricle. In the other 5, there were patterns considered unusual for subjects with RVH having two functioning ventricles, according to the following.

In 3 cases there was much discrepancy between the mean QRS vectors in the horizontal projection contrasted to the frontal projection. For example, left axis deviation was present in the standard and augmented limb leads, while features of isolated RVH were present in the præcordial leads (Fig. 6, left). In 2 other subjects and in one of the latter 3 subjects, there were tall biphasic RS complexes (some over $50 \mathrm{~mm}$. in height) in leads V2 through V4 or V5.

Left ventricular hypertrophy $(\mathrm{LVH})$. Features of $\mathrm{LVH}$ in the pracordial leads were observed in 6 subjects ( 3 with intact A-V valves, 1 with common A-V valve, 1 with tricuspid atresia, and 1 with mitral atresia). In these cases, the mean QRS vector was directed leftward and posteriorly, represented by $\mathrm{rS}$ complexes in V1 and abnormally tall $\mathrm{R}$ waves in V5, or V6, or both (Fig. 5, left).

There were certain findings in the conventional tracings, as noted in the cases with RVH, that are observed uncommonly in subjects exhibiting isolated LVH with two functioning ventricles. 


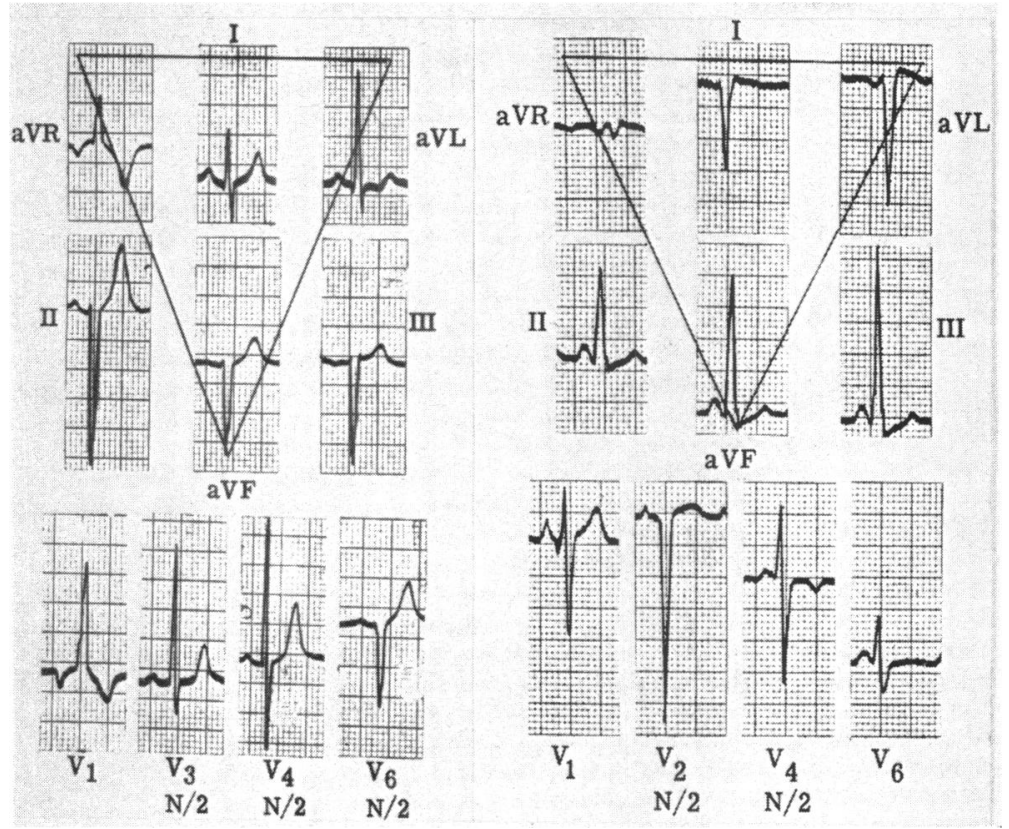

FIG. 6.-Electrocardiogram in two cases of common ventricle with intact A-V valves. Left. 7-year-old boy with non-inversion of the infundibulum. The $\widehat{A}$ QRS axis is of the left axis deviation type. The præcordial leads, however, show complexes consistent with right ventricular hypertrophy. Right. 30-year-old man with inversion of the infundibulum. The $\hat{A}$ QRS axis is directed to the right, whereas the pracordial leads indicate left ventricular hypertrophy. Note the $Q$ in V1.

In 2 of 6 subjects, right axis deviation in the frontal projection coexisted with features of LVH in the præcordial leads (Fig. 6, right). In 2 other subjects, and in both the latter subjects, the terminal appendage of the QRS loop was directed rightward and posteriorly, represented by relatively deep $\mathrm{S}$ waves in V6 (Fig. 4 and Fig. 6, right). In only 2 of 6 cases were the patterns in both the frontal and horizontal projections compatible with the usual type of LVH.

Indeterminate. The indeterminate pattern of hypertrophy was considered present in 9 subjects (8 with intact $A-V$ valves and 1 with common $A-V$ valve). The mean $Q R S$ vectors and their $Q R S$ loops in the horizontal projection, as judged by the pracordial leads, were of 3 types.

(1) The mean QRS vector was directed far posteriorly and the QRS loop was extremely narrow (Fig. 5, right and Fig. 7). This electrical phenomenon was represented by stereotyped rS complexes in all the præcordial leads, owing to the major components of the loop being directed negatively to the isoelectric lines of the axes of all the conventional præcordial leads (Fig. 5, right). These patterns were observed in 4 subjects ( 3 with intact $A-V$ valves, 1 with common $A-V$ valve).

(2) The mean QRS vector was directed far anteriorly, and the QRS loop was extremely narrow, as judged by stereotyped QRs complexes in leads V1 through V6 (Fig. 4, left). These complexes were observed in 3 subjects (each with intact $A-V$ valves).

(3) The mean QRS vector was directed anteriorly and the QRS loop was wide open (Fig. 4, right). This was represented by RS complexes in leads V1 through V6 in one subject (intact A-V valve), and $R S$ complexes from $V 3$ to $V 6$ in 1 (intact $A-V$ valve). The latter subject revealed a QrS pattern in V1.

The mean $T$ vector in the frontal projection varied between +165 degrees and -60 degrees. 


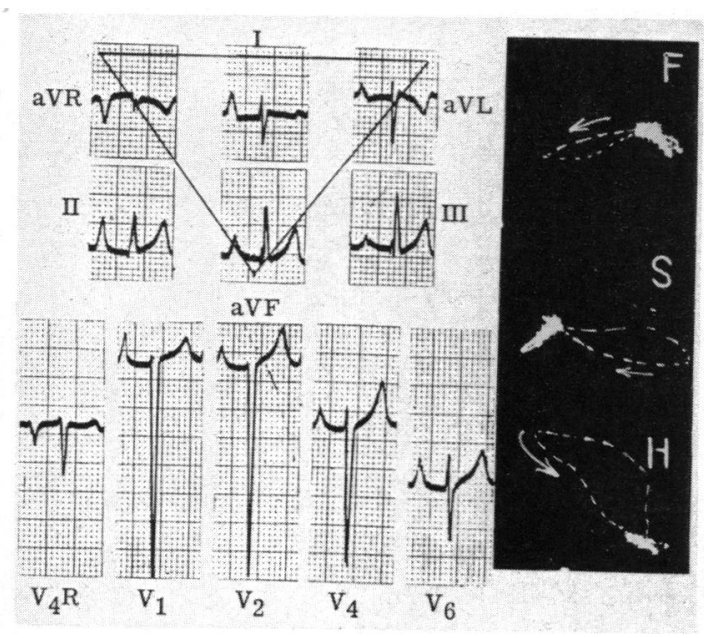

FIG. 7.-Electrocardiogram and vectorcardiogram in an 8-year-old boy with common ventricle, intact A-V valves, and inversion of the infundibulum. Abbreviations as in Fig. 4. Note the indeterminate pattern of hypertrophy in the præcordial leads, namely, rS complexes in V4R-V6. The QRS sE loop (horizontal projection) is directed far posterior and to the right, and lies on the negative aspects of the axes of all conventional praecordial leads. It is apparent from this series of cases with common cardiac ventricle that there was much diversity in the electrocardiographic picture among patients with identical anatomical findings. Moreover, electrocardiographic differences among patients with one type of valvular malformation, as compared to another, were not apparent. These findings are based on too small a number of cases to permit specific conclusions; a larger series might yield a trend not apparent in this study.

It was of interest to note that of the 3 cases with a common $A-V$ valve, only one had the typical mean QRS axis of the "A-V commune" defect. Other malformations of the A-V valves, in conjunction with common ventricle, yielded the following unusual electrocardiographic features.

Of the 2 cases of common ventricle with tricuspid atresia, the mean QRS axis was directed farther to the right than is observed commonly in subjects with tricuspid atresia and a hypoplastic right ventricle (Somlyo and Halloran, 1962; Fig. 5, left). In the one case with mitral atresia, the prevailing pattern in the præcordial leads was consistent with LVH. These signs, however, are uncommonly observed in cases of mitral atresia and a hypoplastic left ventricle.

II. Analysis According to Position of the Infundibular Chamber and State of Pulmonary Flow. As previously mentioned, an infundibular chamber was present in each of the 21 patients with common ventricle. In 10, the infundibular chamber was in the non-inverted position, and in 11, the infundibulum was in the inverted position. In the 10 cases with non-inversion, there were 5 with pulmonary stenosis and 5 without. In the group of 11 patients with inversion, there were 4 with pulmonary stenosis and 7 without.

No electrocardiographic pattern could be correlated with the position of the infundibular chamber, or the state of the pulmonary flow.
The majority of patients exhibited a mean $T$ vector ranging between +75 and +60 degrees. In 8 patients, the $T$ vector tended to point leftward and posteriorly as judged by $\mathrm{T}$-wave inversion or biphasic $\mathrm{T}$ waves in V1, and upright $T$ waves in leads V2 through V6 (6 with intact $\mathrm{A}-\mathrm{V}$ valves and 2 with common $\mathrm{A}-\mathrm{V}$ valve; Fig. 4, left). In 8 cases, the $\mathrm{T}$ vector pointed slightly anterior and leftward, represented by upright $\mathrm{T}$ waves in all the præcordial leads (6 with intact $A-V$ valves, 1 with common A-V
valve, and 1 with tricuspid atresia; Fig. 7). The $T$ vector in the remaining 5 cases showed vector in some cases of common ventricle was also striking. The $T$ waves in 3 subjects were tall and peaked in the left præcordial leads, lead I, or in all of these leads (Fig. 6, left). only 4 cases $(19 \%)$ : of these 4 , the $P-R$ interval was prolonged for age and rate in 3 patients, whereas complete A-V block was present in one. The $P$ waves indicated atrial enlargement in 15 of 21 cases $(71 \%)$ : of these 15 cases, 4 exhibited right atrial enlargement, 8 left atrial 


\section{Discussion}

The electrocardiographic picture of common cardiac ventricle, while often suggestive of this malformation, does not indicate the anatomical state of the A-V valves, the position of the infundibulum, or the presence or absence of pulmonary stenosis. The results reported, however, do provide a basis for the recognition of common cardiac ventricle.

To recognize signs of common cardiac ventricle, one is dependent to a large extent upon the direction of the initial cardiac vectors, as viewed in the horizontal projection. To a lesser extent, common ventricle may be suspected on the basis of (1) unusual processes of depolarization involving the QRS complexes as shown by indeterminate patterns of hypertrophy, and (2) discordancy between the mean QRS vectors in the frontal and horizontal projections of the electrocardiogram.

Evaluation of the significance of the pathway inscribed by the initial cardiac vectors in common ventricle is aided by a brief review of the initial vectors in normal subjects (Scher and Young, 1956; Amer et al., 1960). There is general agreement that the area of the ventricle first to be depolarized is the central portion of the left side of the ventricular septum. Spread of excitation then follows in a left-to-right direction. In the horizontal projection, the mean vector for the first few milliseconds is directed rightward and anteriorly. This sequence of depolarization is represented by $Q$ waves confined to the left præcordial leads of the electrocardiogram. Thus, it seems that the particular direction inscribed by the initial cardiac vectors depends, fundamentally, on the presence of a ventricular septum, and a normally-formed conduction system.

In analysing the conduction system in necropsy specimens of common cardiac ventricle, Lev, Alcalde, and Baffes (1961) showed that the bundle of His and bundle branches ran along the midline of the posterior wall of the common ventricle. It seems logical, then, to predict that the initial cardiac vectors will be altered in those patients whose conduction system is congenitally displaced because of the absence of the ventricular septum. This view is supported by the following observations. In 20 of the 21 subjects $(95 \%)$ in this study, the first 0.01 to $0.02 \mathrm{sec}$. of the QRS complex was altered from the anticipated normal (Fig. 3). Thus, abnormal pathways inscribed by the initial cardiac vectors served as the most constant signs of common ventricle. In the only subject having "septal $Q$ waves" confined to the left præcordial leads, an unusual process of depolarization involving the remaining components of the QRS vector was observed. The QRS loop was directed posteriorly (represented by $\mathrm{rS}$ complexes) in all præcordial leads.

Another valuable feature in suspecting the condition common ventricle was the presence of indeterminate patterns of hypertrophy in the præcordial leads of the electrocardiogram. In 9 of 21 subjects $(43 \%)$, conventional tracings showed stereotyped QRS complexes in the præcordial leads which did not fit into any recognized pattern of hypertrophy. These were distributed as follows: (1) stereotyped rS complexes in leads V1 through V6 were observed in 4 cases; (2) stereotyped QRs complexes in leads V1 through V6 were observed in 3 cases; (3) stereotyped RS complexes in leads V1 through V6 in 1 case, and RS complexes in V3 through V6 in another case.

Another electrocardiographic abnormality, observed not infrequently in common ventricle, was a discrepancy between the pattern of hypertrophy present in the præcordial leads, and the direction of the mean QRS axis in the frontal projection. Thus, common ventricle should be suspected when, in the presence of right axis deviation, the præcordial leads show complexes consistent with left ventricular hypertrophy, or, in the presence of left axis deviation, the præcordial leads indicate right ventricular hypertrophy.

The electrocardiographic findings in our cases of common ventricle may be duplicated by other conditions that share the phenomenon of displacement of the major conduction system such as corrected transposition (Walmsley, 1931), persistent common atrio-ventricular canal (Lev, 1958), and isolated ventricular septal defect of the "A-V commune" type (Neufeld et al., 1961).

In an analysis of 38 cases of corrected transposition, Ruttenberg et al. (1962) found that in 37 cases the initial cardiac vectors were like those that prevail in common ventricle. Moreover, the 3 types of indeterminate pattern of hypertrophy were observed in several cases. In an unreported 
study of 50 cases of persistent common atrio-ventricular canal, we observed rS patterns in the conventional præcordial leads in 6 cases. Thus, in a given case of congenital cardiac disease showing alterations of the initial vectors or indeterminate patterns of hypertrophy (or both together), conditions other than common ventricle cannot be ruled out.

There are, however, certain electrocardiographic findings in congenitally corrected transposition that were rarely found in common cardiac ventricle and may serve as a means of distinguishing these two entities.

(1) Pronounced superior orientation of the initial cardiac vectors in the frontal projection as judged by extremely deep Q waves in lead III; this pattern was observed in 10 per cent of the cases of common ventricle, and in 34 per cent of the cases with congenitally corrected transposition.

(2) Prolongation of the P-R interval was observed in 19 per cent of the cases with common ventricle and in 53 per cent of the cases with congenitally corrected transposition.

(3) Discordance between the frontal and horizontal projections; this feature was not observed among cases of corrected transposition studied by us.

\section{SUMMARY}

The electrocardiograms in 21 cases of common ventricle with transposition of the great vessels were analysed vectorially. Anatomically, cases differed with respect to the position of the infundibular chamber, and anatomical status of the pulmonary and A-V valves. Intact A-V valves were present in 15 cases, common A-V valve in 3, tricuspid atresia in 2, and mitral atresia in one. Obstruction to pulmonary flow was present in 9 cases. The infundibular chamber was located at the right aspect of the base of the heart (non-inversion of the infundibulum) in 11 cases, and at the left aspect of the base of the heart (inversion of the infundibulum) in 10 cases.

In the cases analysed there was no specific pattern that would indicate (1) the association with common ventricle of an anomaly of the atrio-ventricular valvular mechanism, (2) pulmonary stenosis, or (3) the presence of an inverted infundibular chamber.

Three electrocardiographic abnormalities were frequently observed in the material studied: (1) deviation from the anticipated normal of the initial vectors in 20 of the 21 cases; (2) stereotyped complexes in all præcordial leads (rS, QRs, or RS patterns) in 9 cases; and (3) discordancy of the mean QRS vectors between the frontal and the horizontal projections in 5 cases.

The abnormalities given may also be noted in other conditions with congenital displacement of the major conduction system. These include congenitally corrected transposition and anomalies of the "A-V commune" type.

\section{REFERENCES}

Amer, N. S., Stuckey, J. H., Hoffman, B. F., Cappelletti, R. R., and Domingo, R. T. (1960). Activation of the interventricular septal myocardium studied during cardiopulmonary bypass. Amer. Heart J., $59,224$.

Brown, J. W. (1950). Congenital Heart Disease, 2nd ed., p. 229. Staples Press, London.

Campbell, M., Reynolds, G., and Trounce, J. R. (1953). Six cases of single ventricle with pulmonary stenosis. Guy's Hosp. Rep., $102,99$.

Elliott, L. P., Anderson, R. C., and Edwards, J. E. (1964). The common cardiac ventricle with transposition of the great vessels. Brit. Heart J., 26, 289.

Keith, J. D., Rowe, R. D., and Vlad, P. (1958). Heart Disease in Infancy and Childhood, p. 512. Macmillan, New York.

Lev, M. (1958). The architecture of the conduction system in congenital heart disease. I. Common atrioventricular orifice. A.M.A. Arch. Path., 65, 174.

- Alcalde, V. M., and Baffes, T. G. (1961). Pathologic anatomy of complete transposition of the arterial trunks. Pediatrics, 28, 293.

Nadas, A. S. (1957). Pediatric Cardiology, p. 333. Saunders, Philadelphia and London.

Neill, C. A., and Brink, A. J. (1955). Left axis deviation in tricuspid atresia and single ventricle. The electrocardiogram in 36 autopsied cases. Circulation, 12, 612.

Neufeld, H. N., Titus, J. L., DuShane, J. W., Burchell, H. B., and Edwards, J. E. (1961). Isolated ventricular septal defect of the persistent common atrioventricular canal type. Circulation, 23, 685.

Rogers, H. M., and Edwards, J. E. (1951). Cor triloculare biatriatum: An analysis of the clinical and pathologic features of nine cases. Amer. Heart J., 41, 299. 
Ruttenberg, H. D., Elliott, L. P., Anderson, R. C., Adams, P., Jr., and Tuna, N. (1962). Spatial vector and electrocardiographic analysis of thirty-eight cases of congenitally corrected transposition of the great vessels. Abstract presented at the Section on Cardiology, The American Academy of Pediatrics, 31st annual meeting, October 27-28, 1962, Chicago, Illinois.

Scher, A. M., and Young, A. C. (1956). The pathway of ventricular depolarization in the dog. Circulat. Res., 4, 461.

Schmitt, O. H., and Simonson, E. (1955). Symposium on electrocardiography and vectorcardiography. The present status of vectorcardiography. A.M.A. Arch. intern. Med., 96, 574.

Sodi-Pallares, D., and Calder, R. M. (1956). New Bases of Electrocardiography, p. $274 . \quad$ Mosby, St. Louis.

Somlyo, A. P., and Halloran, K. H. (1962). Tricuspid atresia. An electrocardiographic study. Amer. Heart J., 63, 171.

Spitzer, A. (1951). The Architecture of Normal and Malformed Hearts, ed. M. Lev, and A. Vass, p. 64. Thomas, Springfield, Illinois.

Taussig, H. B. (1960). Congenital Malformations of the Heart, Vol. 2: Specific Malformations, 2 nd ed., p. 325. Harvard University Press, Cambridge, Massachusetts.

Van Praagh, R., Zacharioudakis, S., and Keith, J. D. (1962). Electrocardiogram in common ventricle. Circulation (abstract), 26, 798.

Vince, D. J., and Keith, J. D. (1961). The electrocardiogram in ventricular septal defect. Circulation, $23,225$.

Walmsley, T. (1931). Transposition of the ventricles and the arterial stems. J. Anat. (Lond.), 65, 528.

Ziegler, R. F. (1951). Electrocardiographic Studies in Normal Infants and Children. Thomas, Springfield, Illinois. 